\title{
19 \\ A Trip to the Mountaintop
}

\author{
Jenny Virdi Kroik
}

\section{Introduction by Åsa Virdi Kroik}

My daughter wrote this story. When she was about six years old, she participated in a revitalisation project that I was the coordinator for while working in Nord-Trøndelag on the Norwegian side of south Saepmie. It was one of several revitalisation projects I coordinated between 2008 and 2010. We worked with language and culture revitalisation in different ways, and this project was designated for the children from six-10 years old, but it also became a project for the fathers/men as I was the only woman to participate. I think that the reason for this specific project's attraction for the men was that they felt comfortable with the mountain environment and the activities we performed. Two of them were full-time reindeer herders and the others were familiar with reindeer herding. The project was very successful and several participants, adults and children, asked for it to be repeated many years later. After the first year's success, we did the camp again at the same dates in August. We had fantastic luck with the weather in both years and it's difficult to differentiate the two camps from each other in my memory. As my family and I later moved from the area and I took another job, I did not have time to coordinate any more camps, but it's not impossible that we will do it again another summer. 


\section{A trip to the mountaintop}

$\mathrm{Hi}$, my name is Jenny and I'm going to tell you about the time we went to Sijliesjaevrie.

One year, maybe it was 2010 or 2011 , or maybe even as late as 2012 (though probably not), we were living in a big red house in north Sweden, and my mom arranged this trip to a mountain close to us. We got tents and reindeer skins and basically everything we needed. We lived next to a football field (that no one ever used, just so you know) and we had a pilot for the helicopter, which landed on the football field, and which was supposed to take us to Sijliesjaevrie and bring us back. I was with my two cousins, their dad and their dog, as well as my parents. So we took everything - bags and other things - to the field where the helicopter would come. We put everything in the helicopter and flew up. While we were up there, the pilot took us on a small tour around the village that we lived in and told us about everything.

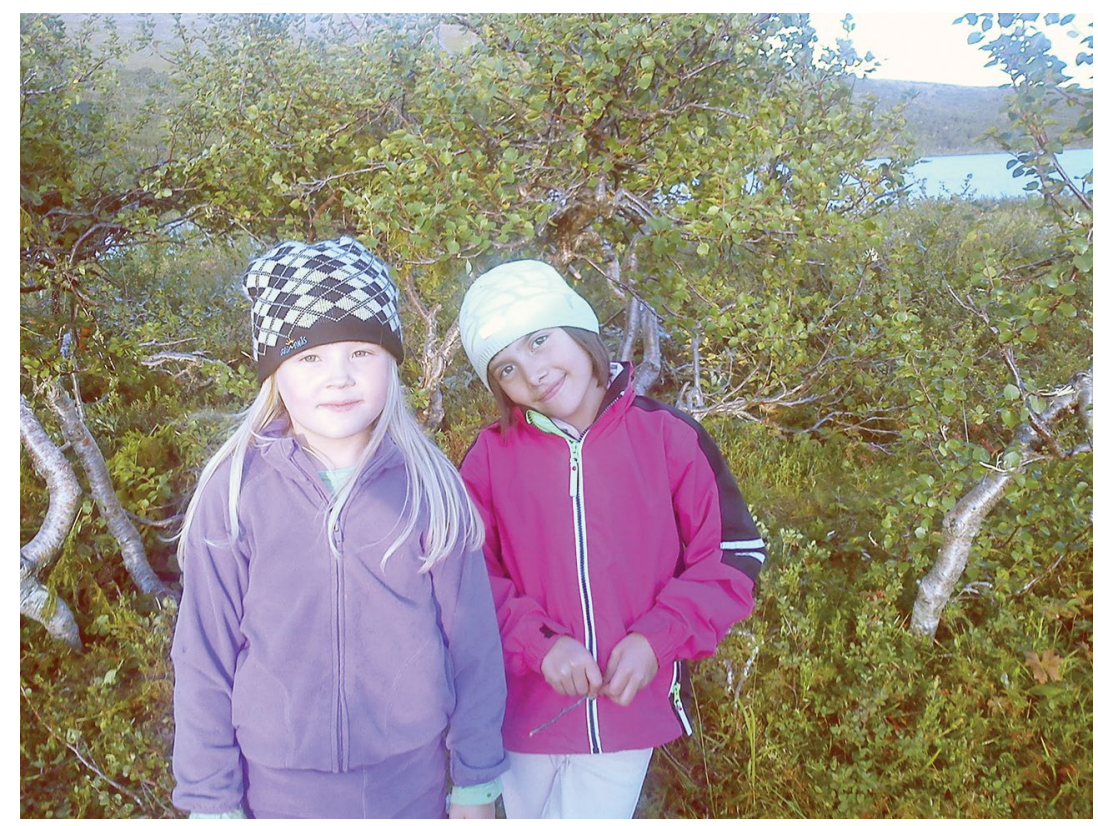

Figure 14. Jenny Virdi Kroik (right) and Ristin Kristoffersson during a trip to the mountaintop.

Source. Photographed by Åsa Virdi Kroik, Sijliesjaevrie, August 2010. 
When we got up to the mountaintop, my two laevie (relatives), Ella and Ristin, and I inspected the area. There wasn't much there, only a few bushes and there was a very small river further down from our tents that we'd set up. It was windy and sunny. It was a good big area with small trees that were about our height, and we found a bush that had branches that were a little thick. We started cutting some pieces and making passages through the bush. We were planning on making a small tree house or 'bush house' and there was no need for a roof since it was a bush (Figure 14).

So, we worked for maybe 30 minutes, till we helped my parents and my cousins' father set up tents, and then started to eat. After that, I guess we kept working. We spent two days there, but I really don't remember everything. Anyway, here are some moments that I remember very clearly:

1. I might be totally wrong about the bush tree thing (but we did work with it so don't be confused) but I think we played around and recorded ourselves with my new video camera that I had gotten once the tents were up. I remember we'd only play around and I'd be the one talking.

2. The first night that we were there, Ella, Ristin and I decided to sleep together in one tent. It started out well, but then someone moved to the other tent, then another one, then one came back, then the other came back, and so on.

3. My relatives' dog, Kejio (I think that was her name), amused herself by chasing small animals.

4. Oh! And when we were going to leave, I put my knife on a rock next to our bush house and it disappeared. How? I don't know. But given that it was windy, it might have just blown away.

On our way home we could choose to walk, ride the helicopter, or ride horses. Ristin and I rode horses, meanwhile my dad, Ella, and her dad, along with Kejio took the helicopter. It was a fun experience.

Sorry, but that's all I remember. 
This text is taken from Indigenous Efflorescence: Beyond Revitalisation in Sapmi and Ainu Mosir, edited by Gerald Roche, Hiroshi Maruyama and Åsa Virdi Kroik, published 2018 by ANU Press, The Australian National University, Canberra, Australia.

doi.org/10.22459/IE.2018.19 